\title{
Client Participation in Moral Case Deliberation: A Precarious Relational Balance
}

\author{
F. C. Weidema • T. A. Abma \\ G. A. M. Widdershoven • A. C. Molewijk
}

Published online: 27 July 2011

(C) The Author(s) 2011. This article is published with open access at Springerlink.com

\begin{abstract}
Moral case deliberation (MCD) is a form of clinical ethics support in which the ethicist as facilitator aims at supporting professionals with a structured moral inquiry into their moral issues from practice. Cases often affect clients, however, their inclusion in MCD is not common. Client participation often raises questions concerning conditions for equal collaboration and good dialogue. Despite these questions, there is little empirical research regarding client participation in clinical ethics support in general and in MCD in particular. This article aims at describing the experiences and processes of two MCD groups with client participation in a mental healthcare institution. A responsive evaluation was conducted examining stakeholders' issues concerning client participation. Findings demonstrate that participation initially creates uneasiness. As routine builds up and client participants meet certain criteria, both clients and professionals start thinking beyond 'us-them' distinctions, and become more equal partners in dialogue. Still, sentiments of distrust and feelings of not being safe may reoccur. Client participation in MCD thus requires continuous reflection and alertness on relational dynamics and the quality of and conditions for dialogue. Participation puts the essentials of MCD (i.e., dialogue) to the test. Yet, the methodology and features of
\end{abstract}

F. C. Weidema · T. A. Abma - G. A. M. Widdershoven · A. C. Molewijk

Department of Medical Humanities, Free University Medical Centre,

Van der Boechorstraat 7, 1081 BT Amsterdam, The Netherlands

e-mail: t.abma@vumc.nl

G. A. M. Widdershoven

e-mail: g.widdershoven@vumc.nl

A. C. Molewijk

e-mail: b.molewijk@vumc.nl

F. C. Weidema $(\bowtie) \cdot$ A. C. Molewijk

GGNet Expertise Centre, P.O. BOX 2003, 7230 GC Warnsveld, The Netherlands

e-mail: f.weidema@ggnet.nl 
MCD offer an appropriate platform to introduce client participation in healthcare institutions.

Keywords Moral case deliberation - Client participation · Dialogue · Inclusion · Organization

\section{Introduction}

Internationally, interest in the active involvement of clients in daily healthcare practice is increasing. Research focuses on how and why to involve clients in practice and what surplus value can be found in their active participation (Agich 1991; Schicktanz et al. 2008). Recent European publications articulate participation of clients in clinical ethics consultation meetings, in which a specific case concerning a specific client is at stake. The client in the case at hand can either be involved in the deliberation process, or be absent (Fournier et al. 2009; Newson 2009; Neitzke 2009; Rari and Fournier 2009; Førde and Hansen 2009). Including client perspectives in moral decision-making is motivated by ethical and political considerations (e.g., client autonomy, shared responsibility in decision-making, reequilibration of the doctor-client relationship, empowerment) (Rari and Fournier 2009; Fournier et al. 2009).

In the Netherlands, initiatives concerning moral reflection on the shop floor by healthcare professionals themselves are increasing (Weidema et al. 2011; Dauwerse et al. 2011). Moral case deliberation (MCD) is a particular example of such an initiative, differing from approaches such as ethics committees or ethics consultation (Aulisio 2003). Within a MCD, a multidisciplinary group of healthcare professionals meets to deliberate systematically on a moral case from their own practice. The meetings are facilitated by a specifically trained MCD facilitator following a structured conversation method. The aim of an MCD session is to create a dialogue in which various perspectives on a case are presented and brought into dialogue (van der Dam et al. 2011). Participants are challenged to explore both their thinking and the issues within the case in order to create a mutual learning process by the confrontation of perspectives (Bohm 1996). An MCD session does not transcend practice, but systematically explores facts and values that are at stake in a case. MCD is radically concrete, focusing on the actual experiences and reasoning of participants (Gadamer 1960; Irvine et al. 2004; Widdershoven et al. 2009). Dialogue is seen both as a means and an outcome of an MCD session (Schwandt 2001; Molewijk et al. 2008a; Greene 2001; Abma et al. 2009a). To accomplish this, an attitude that fosters dialogical dynamics is required. Regulative conditions for this attitude are: equal participation and appreciation of mutual differences. These conditions support constructive relational dynamics. A dialectical process - the conversational spaceopens up to the content of the session, aiming at creating a learning environment by exploring differences. In this way, experiential knowledge is constructed amongst participants (Kolb et al. 2002). Those involved in the organization of MCD sessions note these constitutional and regulative rules as essentials distinguishing MCD from other meetings in healthcare practice (Weidema et al. 2011). 
Recently, clients have been actively involved in MCD sessions in a number of Dutch healthcare institutions. Healthcare professionals as well as client participants are invited to bring in cases for deliberation. In such cooperation between professionals and clients (transdisciplinary groups), tensions due to differences in position, interests, language and communication style may arise (Holmesland et al. 2010). This paper discusses examples of client participation in two different MCD groups in psychiatry. Rather than arguing that clients should be involved in clinical ethics support activities, this paper explores the actual experiences of client participation in MCD, giving a voice to all stakeholders involved. In doing so, this empirical research is a way of contributing to the theme of client participation and working in transdisciplinary groups in clinical ethics.

Data presented are part of a larger study on the implementation of MCD. In this paper, we aim at answering the question: What are actual experiences with client participation in MCD and how does client participation affect dialogical and relational dynamics?

\section{Method}

\section{Setting}

GGNet is a large mental healthcare institution in the east of the Netherlands. MCD was introduced in 2004 as part of a project on 'Reduction of Coercion and Restraint'. The GGNet Expertise Centre fosters an MCD Steering Group that monitors quality and development of the MCD activities organization wide (Molewijk et al. 2008b). By now, halfway through 2010, MCD is a familiar concept within GGNet. Over forty groups have MCD sessions either in ongoing groups, within the context of a series of MCDs, or incidentally in the case of a specific dilemma. Halfway through 2008, seven out of these forty groups introduced client participation. Clients active in MCD sessions are either members of the client council, patient experts or, incidentally, clinically admitted clients. As part of a 3 year study on the implementation of MCD data were collected over the years 2008-2010. This paper is based on these data.

\section{Theory and Design}

To monitor the process of client participation in MCD, a responsive process evaluation was chosen as the study design. This design is driven by the same democratic, participative and dialogical values as MCD itself (Widdershoven et al. 2009; Abma et al. 2009a). Using a responsive evaluation strategy, active inclusion of an optimum of all stakeholders is obtained, thereby meeting democratic, dialogic and participative principles simultaneously (Widdershoven et al. 2009). In responsive evaluation the issues (expectations, concerns, controversies) of all stakeholders are investigated to obtain a rich understanding of the evaluated practice from insiders' perspectives (Stake 1975, 2004). Responsive evaluation (compare Guba \& Lincoln's Fourth Generation Evaluation 1989) insistently includes the voices of all 
stakeholders in the evaluated process; not only as information givers, but also as advisors and partners (Greene 1988). Its aim is to enhance the mutual understanding between stakeholder groups as a vehicle for practice improvement. The process is cyclical: stakeholder issues are first gathered and discussed among groups with converging interests (homogeneous groups), and later used as input for hermeneutic dialogues between groups with diverging interests (heterogeneous groups). These dialogues do not aim at generating consensus per se, but at collecting meaningful issues that are relevant for the stakeholders themselves. Also, the meetings aim at facilitating mutual learning by responding to the various perspectives presented during the sessions (Greene 2001; Abma 2006).

\section{Data Collection}

The data collection was iterative and cyclical; input from former stages provided input for later stages (Paulus et al. 2008). First, informal conversations were held with representatives from all stakeholder groups: (client) participants, local coordinators (nurses responsible for the daily organizational aspects of the MCD sessions, and functioning as intermediary between team, manager, conversation facilitator and the MCD steering group of the Expertise Centre), managers, MCD facilitators and members of the MCD steering group. The topics emerging in these conversations were used as input for semi-structured interviews in the next stage and incorporated in evaluation forms which were filled out by all participants at the end of every single MCD session.

Next, 15 semi-structured interviews were held; five local coordinators, five MCD facilitators and five managers were interviewed. The interviews lasted about 1.5 hours, were tape recorded with consent, and fully transcribed. When no new issues were found, this phase was ended (principle of saturation) (Charmaz 2000). Based on these interviews another, refined topic list was created. This was used for a focus group with five (out of 11) local coordinators and a focus group amongst the four client participants involved in MCD sessions. On request of the local coordinators, a heterogeneous group specifically dealing with the issue of client participation, amongst them three local coordinators (out of 11) and four MCD facilitators (out of six), took place. The focus groups and heterogeneous group were moderated by the researcher (FW) and the program leader of the MCD steering group (BM). The sessions were tape-recorded and entirely transcribed. Three (audio taped) oral evaluations, held in every MCD group once a year, were also included in the data. Furthermore, extended evaluation questionnaires taken amongst all MCD participants once every year, were used. These extended forms were also filled out by client participants, MCD facilitators and local coordinators. Also, e-mail contacts with stakeholders involved in the process of MCD sessions concerning the subject of client participation were taken into account within the analysis.

\section{Limitations of the Study}

Throughout the data collection process, the largest body of data came from professionals in the MCD sessions. We collected less data among client participants in proportion to the data from professionals. 


\section{Data Analysis}

The data analysis was done inductively, allowing themes to pop up by studying the data closely. In order to approach the data and the practice in an open-minded way, no theory was applied to the analysis of the data beforehand (compare grounded theory, Charmaz 2000). The analysis was conducted following two lines of inquiry: first, in the inductive phase positive and negative aspects of client participation mentioned by stakeholders were assembled and clustered. It appeared that quotes from the groups on client participation referred to fundamental values within the MCD dialogue (such as: equality of voices, willingness to explore, frankness in speaking, postponing judgments etc.). Therefore, these values became a second focus in the analysis, comparing the practice of client participation in MCD with the aims and values of MCD. Following these two lines, an analysis was obtained focusing on the impact of client participation on dialogical and relational dynamics in MCD practice-and beyond.

\section{Quality Procedures}

For this research, the principle of triangulation was applied (Maxwell 1996), using several sources of data and several (both qualitative and quantitative) methods of data collection. All oral material was tape recorded and interviews were fully or partially transcribed. The analyzing process was done under supervision of three senior researchers from the university, in close contact with the manager of the expertise centre and the GGNet MCD Steering Group. Findings were shared and discussed in the research team. Throughout the analysis, notes were made in a logbook by the principal researcher in order to make the process as transparent and retraceable as possible. Finally, a member check was organized to optimize internal validity. This concerned the analysis of the data that was done amongst the stakeholders involved. In doing so, only incidentally, hiatuses, blind spots or incorrect interpretations were found and adjusted.

\section{Research Ethics}

All respondents in this research participated voluntarily and were informed about this publication and gave their consent. The identity of the respondents is not made explicit. IRB approval was not required according to Dutch law.

\section{Results}

Results will be presented by describing two cases. In section "Analysis", we will present a comparison between case 1 and case 2 .

\section{Case I: Management Initiative and Unequal Participation}

After a positive evaluation of the MCD sessions in the reduction of coercion and restraint project, the manager of an acute admission ward decided to continue MCD 
sessions in his team on a regular basis. He decided to apply regulations for attendance more strictly: participating in MCD would become part of the annual, individual reviews for nurses. He also suggested the introduction of active and ongoing client participation in the MCD sessions, in order to provide the possibility of discussing a case on an equal level. In cooperation with the MCD steering group of the expertise centre, the manager decided to invite participants coming from the general client council at GGNet.

The members of the client council were eager to accept the invitation. Halfway through 2008, one member became a permanent participant in the sessions. The client participant took part in all aspects of the MCD-process: providing casuistry to deliberate on, actively participating in the sessions by sharing his perspective, and being involved in organizational aspects and preparations of the sessions.

\section{In Advance: Tensions About the Idea}

Despite enthusiasm and eagerness amongst client council members, the healthcare professionals were reluctant towards the initiative. The idea of involving client participants invoked strong feelings of insecurity and vulnerability. Professionals doubted the reliability and integrity of (ex) clients. Furthermore, professionals felt uneasy when a client with a history (and maybe a future) of admissions on the ward would be involved. Client participants experienced the doubts concerning their reliability as particularly painful.

The team reacted with fear. The whole team did. They feared the appeal of MCD in showing your own feelings, your own weaknesses or pitfalls in relation to clients (ind. interview, local coordinator).

Even before we were introduced, our integrity was already questioned. Nurses said: 'I do not dare sharing my deepest thoughts in their presence.' I found that really hard in the beginning. Really hard (ind. interview, client participant).

Local coordinators were sensitive to the reticence of their colleagues and tended to postpone the participation of (former) clients. They stated that professionals were not ready for client participation in their group, feeling unsafe and caught unprepared.

I tried to hold back for quite a while (...). At some point the manager started pushing that we should give it a go. But the nurses did not like the idea at all (indiv. interview, local coordinator).

It was a very precarious issue! We [nurses-FW] talked it over many times. People felt... distrust towards (...) the client participants (focus group, MCD facilitator).

The manager expected resistance would not pass spontaneously. Although he understood the reticence of the professionals, he believed client participation deserved a fair chance before a final judgement could be made. The MCD facilitator - allied to the MCD steering group_agreed with this viewpoint. After the decision to continue, the local coordinators became more cooperative. The initiative 
was announced in the local newsletter and soon after that client participation was regarded as a given fact.

Only by having the experience of [client participation in-FW] MCD (...) one can learn: 'hey! Talking to [clients-FW] actually is possible!' (focus group, MCD facilitator).

\section{Openness for Positive Lessons}

So the client participant joined the MCD sessions, actively contributing to the content. Also, casuistry was brought in by both professionals and the client participant. Evaluation forms of these MCD sessions showed appreciation for the added viewpoint the client participant brought in. The client perspective appeared much richer when brought in directly rather than portrayed by professionals, as was done earlier.

Listening to the viewpoint of the client council member is sometimes very clarifying, because as professionals you might think you are at the right track and from their perspective this appears not to be the case (focus group, local coordinator).

The client participant in turn showed eagerness to learn by considering the viewpoints of the professionals. As a result, distinctions between 'us and them' were softened. The client participant expressed experiencing a great sense of emancipation by gaining a voice in deliberating on such precarious casuistry. Conversation facilitators considered this a big step forward in emancipating client contribution to good care. As time went by and routine built up, reluctance amongst professionals diminished and-under conditions - the client participant was accepted as a member of the group.

I came to realise some clients mean really hard work for professionals. With this, MCD taught me to perceive professionals as fellow-human beings. To me this awareness works out very connecting (group interview, client participant). My participation in MCD really means to me a step towards emancipation of clients: we are communicating directly. We do not speak about each other, we all have equal voices (group interview, client participant).

I thought client participation really was (...) immensely emancipatory (indiv. interview, MCD facilitator).

\section{Reticence}

Still, despite this appreciation and softening of the us-them distinction, doubts amongst professionals participating in the sessions still existed below the surface. At moments, some professionals noted on the evaluation forms that they did not dare speaking out frankly. They felt vulnerable in the presence of client participants. Referring to (former or possible future) care relations with the client, they feared information from the sessions might be 'abused'. Noticing this reticence of professionals, client participants realized that it would not be an easy process to become really accepted as partners. 
We have been working on this for so long. It takes an enormous amount of perseverance because amongst the employees there is still so much fear concerning our reliability. By now we know this will take endurance and patience (group interview, client participant).

\section{Negative Sentiments Easily Return}

When an incident in the group occurred, the 'them and us distinction' easily returned: information from casuistry from one of the MCD sessions appeared to be circulating amongst clinically admitted clients on the ward. Professionals immediately stated they knew where the information must come from: they supposed the participant from the client council was leaking confidential information. Professionals felt confirmed in their previous presuppositions concerning the lack of reliability and integrity of the client council member. According to the local coordinator, they judged the state of affairs firmly. A rush of reactions amongst subgroups of all stakeholders in the process-mainly via e-mail contact-resulted in a more explicit view on criteria for client participation:

[before the incident-FW] things had settled just a bit, and now colleagues focus on client participation again. And I feel this is not fair towards our client participant.

What do you mean 'towards him'?

Well... suspicion is coming back.

Are they afraid he is leaking also?

Well, they are afraid information is being leaked by client participants in general (focus group, local coordinators).

Professionals proposed contra-indications for participating in MCD in terms of psychopathology (no personality disorder) or in terms of attitude (not too silent, not too prominent). Client participants should meet these criteria in order to be able to join sessions.

On the other hand, MCD facilitators stressed the learning potential of critical situations such as the incident that occurred. They interpreted these hard moments as potentially constructive:

(...) We immediately said: we don't want participants in our group who enter short after admission and have a personality disorder, well...with such participants you can expect problems!(focus group, local coordinator).

I believe that by such trifles a group can mutually grow. I mean, dealing with those storms in the process contributes to surpassing us-them distinctions (focus group, MCD facilitator).

During the oral evaluation of these MCD sessions the manager appeared firmly opposed to the suggestion to postpone client participation because of the professionals' reticent frankness. According to the manager, professionals should learn to see clients as full-fletched conversation partners. MCD is the ideal platform to practice just that. The revived feelings of distrust and discomfort were not 
discussed amongst clients and professionals together. Driven by the managers' ideal, MCD was continued including client participation.

Professionals did not appreciate my presence at all. They did not feel safe [after the incident-FW]. But no one asked how I felt. But I do sit there, alone, around the table amongst all professionals!(group interview, client participants).

[Participation-FW] isn't secured. The sessions simply continue, also if there is no client participant present (group interview, client participant).

I don't think any of my colleagues would say: 'they múst be included!' No one would shout if a client participant isn't present: 'this is unacceptable!' (...) (focus group, local coordinator).

\section{Summarizing}

In this case, client participation was induced by management. The introduction of client participation resulted in diminishing the initial reluctance amongst professionals. The addition in viewpoints was appreciated. Yet, professionals now and then kept reporting not to feel at ease, and to miss the frankness at which MCD aims. As an incident occurred, reluctance revived. In this case, the balance between positive and negative aspects of client participation remained precarious and was easily disturbed. This disturbed balance did not become a subject in the sessions, so that participants remained talking about rather than with client participants.

\section{Case II: A focus on Content and Numerical Equality}

The second case concerns a series of moral deliberations focusing on moral questions related to sexuality and intimacy in a mental healthcare institution. This issue was brought up by a study group of nurses, who brought it to the notice of the board of directors. The board of directors asked the nurses group to explore the subject and to organize this together with the client council and the GGNet MCD steering group. The goal of this project was, on the one hand, to stimulate dialogue on this subject and, on the other, to provide insights, viewpoints, principles, etc. for making an institutional policy on the subject. Ten moral case deliberation sessions were scheduled to explore the issues amongst people involved. The project group openly invited healthcare professionals, members of the client council, and members of the family council to participate voluntarily and on an individual basis. Six out of the ten sessions took place in a fixed group, having the same participants. The representation of client participants, family members and professionals was more or less equal. In four out of the ten sessions, everybody was welcome to subscribe for participation. In these four open sessions, also clinically admitted clients participated.

\section{A Shared Interest in Content}

Because the subject of intimacy and sexuality in mental healthcare was something of a personal interest, participants committed to the MCD sessions. This 
commitment worked out positive: everybody joined for the sake of the subject, not as a member of an existing team but on an individual basis in a new temporarily group. Also, people came together because of a framed, clear goal: contributing to a proposal for a policy on intimacy and sexuality.

We did not know in advance who would be joining those sessions. But we did know the subject of the sessions and we shared an interest concerning this. Therefore, the tension was quite different from sessions in ongoing groups in for example a clinical team (indiv. interview, MCD facilitator).

We came together to sort out and explore our own main issues concerning policy on sexuality; what should be in it, and what not. This was a joint goal: creating building blocks together, sharing responsibility of what would come out of the sessions (focus group, local coordinator).

\section{Individuals Rather than Groups}

Throughout the sessions, all groups were equally represented. Rather than blocks or camps or teams, people joined on an individual basis. Participants easily mixed because they did not know each others' relation with the institution, or regarded it as irrelevant. The point was to join together and get to the heart of a case, without prior problematic relations or shared admission histories-although it was known that some participants had a shared history in care.

I think it is of substantial importance (...): working towards a shared goal. That is so much a different situation from a client participant shoving on in MCD sessions in a clinical team (focus group, local coordinator).

There was no 'block of people'. We were all individuals, all different people (focus group, local coordinator).

Within the sessions people worked in conformity with the MCD method: listening to each other, taking new perspectives into consideration. Also, throughout the sessions there was a lot of laughter amongst participants. Participants reported that they learned a lot. In the so called open sessions, they said the atmosphere was friendly, easygoing and willing.

I never learnt as much as I did in those MCD sessions. There was so much space to share experiences. The method created a safety to share those experiences in an atmosphere of safety. That was really positive (focus group, local coordinator).

The MCD facilitators tended to protect client participants to some extent. They felt that there was great emancipatory power in client participation and therefore it should be cherished. MCD facilitators suggested that, because of the equal numerical representation of all participant groups, client participants weren't outnumbered by a possible intimidating group of professionals. In their perception, this was vital for the process of inclusion during the MCD sessions. 
Within these [open-FW] MCD sessions, clients other than members of the client council joined in. Because there were five of them, it all went well. But you should not send them to a MCD on their own. They would not be able to maintain themselves. But once they are in the company of fellow-client participants, they are okay (focus group, MCD facilitator).

I realise it cannot be easy to join a relatively closed group all on your own. I mean: being the only client in a nursing team (indiv. interview, $M C D$ facilitator).

\section{Professionalism and Diminished Frankness}

Just as in case I, professionals reported they felt reticence in speaking out frankly. They explained this by referring to the presence of client participants (members of the family council are not mentioned by them in this respect), as well as the subject of the sessions, namely sexuality and intimacy. Interpreting this, MCD facilitators believed 'openness' was understood by the professionals as having to talk about personal experiences concerning sexuality. Therefore, during the sessions the MCD facilitators stressed that 'openness' means receptivity towards perspectives and reasoning from participants (and not to personal sexual experiences). In other words, the reluctance in speaking out frankly was related to the subject of the sessions, not to the background of fellow participants. Just as in case I, conversation facilitators mitigated reticence or the feeling of not being safe. They said professionals tend to approach MCD as something big and personal, instead of just entering the dialogue at stake without preconceived notions. In evaluation forms, feelings of reticence diminished as time went on and experience grew.

In the beginning I missed frankness, because we did not know each other (evaluation form participant - professional).

some reticence (evaluation form, participant-professional).

It is not the purpose to talk about personal experiences concerning sexuality (laughter). It is not the point to become less professional, but to be receptive to the subject in the context of professional practice. That's what clients need! (focus group, MCD facilitator).

\section{Summarizing}

In this group, both the focus on a shared problem and the numerical equality within the group proved to be positive for client participation. Initially, as in case I, there was some reluctance towards working in this mixed setting. This resulted in reticence in meeting the principles of MCD such as 'speaking frankly'. This attitude diminished as experience evolved. Focusing on the content of the sessions rather than questioning the composition of the group, all participants became full fletched members of the group. The group cooperation developed positively, and there was even an open attitude towards participation of people outside the fixed group during the four 'open sessions'. 


\section{Analysis: Similarities and Differences in the Cases}

In both cases a similar movement in group dynamics is present: first professionals show resistance or reticence, but as time goes by the differences in background of separate participants become less of an issue and the us-them distinction diminishes. Yet, the cases differ in terms of organizing structures, composition of the groups and attitude (see Table 1). These aspects affect the dynamics in both the relations and the dialogue. In the next paragraph these differences are analyzed. Essential values related to MCD methodology will be addressed, referring to dialogical and relational dynamics.

\section{Organization of the MCD Sessions}

\section{Ownership and Attendance}

In case I, a top-down and pragmatic introduction of client participation is chosen by the manager to overcome reluctance of professionals by experience. Professionals experience little space to express, share, or explore feelings or ideas concerning this novelty. As attendance is obligatory, they have to accept the decision. Professionals deal with the given situation by formulating criteria client participants should meet in terms of psychopathology and their attitude during the sessions. This enforces stereotyping, so that client participants find it more difficult to become a regular member of the group and equal partner in the dialogue. In case II a bottom-up introduction of client participation results into a more reflective and receptive attitude, and the potential of constructing a solid group cooperation process. Space is available to explore possible feelings concerning the cooperation of nonprofessional participants in an atmosphere of little system pressure. As participants join the sessions voluntarily and on an individual basis, they develop a sense of joint ownership.

\section{Content and Time Path}

In case I, client participation is introduced in an already existing, rather homogenous group with an open agenda. Beforehand, it is not clear for MCD participants what the surplus value of client participation might be. Also, nurses wondered what issues they can and cannot bring in during the sessions. From their perspective, the introduction of client participation disturbs the merits of the existing MCD routine. In case II, the MCD sessions come with a clear time path and a focus, namely on issues concerning sexuality and intimacy in mental healthcare. There is a shared goal, and as a consequence clear structure: sharing experiences and working towards the formulation of policy items on the subject. The relevance of the added viewpoint from non-professionals is clear considering the aim of the sessions: learning to create a dialogue about a precarious subject. There are no questions about the value of their potential contribution. 
Table 1 Client participation in moral case deliberation

\begin{tabular}{|c|c|c|}
\hline Main theme & Case I: sub themes & Case II: sub themes \\
\hline \multirow{4}{*}{$\begin{array}{l}\text { Organization of } \\
\text { the MCD } \\
\text { sessions }\end{array}$} & $\begin{array}{l}\text { 'Ownership' of client } \\
\text { participation: manager }\end{array}$ & $\begin{array}{c}\text { 'Ownership' of client participation: GGNet } \\
\text { nurses study group, Board of Directors }\end{array}$ \\
\hline & Obligatory attendance for profs & $\begin{array}{l}\text { Voluntary attendance (invited by project } \\
\text { leader) }\end{array}$ \\
\hline & Content: open & Content: sexuality/intimacy \\
\hline & Time path: ongoing sessions & Time path: slot of 10 sessions \\
\hline $\begin{array}{l}\text { Motivation for } \\
\text { client } \\
\text { participation }\end{array}$ & External, enforced by management & $\begin{array}{l}\text { Intrinsic, decided by nurses and MCD group } \\
\text { together }\end{array}$ \\
\hline \multirow[t]{2}{*}{$\begin{array}{l}\text { Compilation of } \\
\text { the group }\end{array}$} & $\begin{array}{l}\text { History: just nurses in MCD, } \\
\text { coming from one existing team/ } \\
\text { ward }\end{array}$ & $\begin{array}{l}\text { Client participation from the start, group } \\
\text { members from all over the organization }\end{array}$ \\
\hline & $\begin{array}{l}\text { Sole client amongst healthcare } \\
\text { professionals }\end{array}$ & $\begin{array}{l}\text { Equal numerical representation by } \\
\text { professionals, family members, client } \\
\text { participants (formerly and clinically } \\
\text { admitted) }\end{array}$ \\
\hline $\begin{array}{l}\text { Dealing with } \\
\text { vulnerabilities }\end{array}$ & $\begin{array}{l}\text { Homogenous talking about client } \\
\text { participation outside MCD }\end{array}$ & $\begin{array}{l}\text { Reflecting upon feelings of vulnerability } \\
\text { related to content during MCD }\end{array}$ \\
\hline
\end{tabular}

Factual differences between case I and case II regarding client participation in MCD

\section{External or Internal Motivation for Client Participation}

In case I, due to the introduction of client participation by the manager, professionals were not intrinsically motivated for client participation in 'their' MCD sessions. After some time they do show appreciation of the added perspective of the client participant, but these positive findings do not result in them fully embracing client participation. Motivated by regulations, professionals endure client participation. This results in sustaining doubts about client participants' reliability, capacities and remaining asymmetries, emerging when an incident occurs. In case II, client participation is anchored beforehand and a known fact from the beginning. Also, participants join the sessions because of their involvement in the subject. So, participants are intrinsically motivated to attend, focusing on the content and the aim of the slot of the sessions.

\section{Compilation of the Group}

\section{History of a Group}

An important factor concerning relational dynamics in case $\mathrm{I}$ is the fact that a sole client participant joins the sessions in an existing group of professionals - a nursing team. By a shared MCD and working history, this group of professionals already has 
its own culture, language, rules and codes. The client participant thus needs to tune into these habits, in order to become integrated in the group (Holmesland et al. 2010). In case II, more than one client participant joins in from the beginning. Thus, client participants are not as exceptional as in case I. Here, the cultural aspects are not as prominent as there is no group identity already. With this, equality of voices can be more easily accomplished. This equality of voices is an important principle and value within MCD, stimulating all perspectives to be taken into consideration.

\section{Numerical Representation: The Odd One Out?}

In case I, it seems as if the client participant does not fully overcome the status of being a (former) client. Stereotyping remains - to and fro-and asymmetries in terms of (former) care relations still affect relations now and then. Despite this circumstance, the client participant, being alone in a group of professionals, tries to become a full fletched member. It seems as if he keeps a guest status, remaining an exception in the group. When an incident occurs, client participation appears precarious, challenging and sometimes problematic. Moreover, when professionals outnumber client participants, equal input is at risk (Reiter-Theil 2003; Newson et al. 2009; Neitzke 2009), pointing at the importance of so called 'proportional deliberation' in which equal numerical representation of different backgrounds of participants is pursued (Karpowitz et al. 2009). Perhaps another social phenomenon pops up here: if a certain perspective (i.e., client) is represented by only one person, the risk might increase that his/her viewpoint is perceived as a 'typical' or a stereotype perspective of 'the' client in general, rather than an individual perspective. In the second case, a group of non-professionals joins the sessions, namely a number of client participants and a number of family council members. As voices are therefore more equally represented (proportional deliberation; Karpowitz et al. 2009), integration grows organically and relatively smooth.

\section{Dealing with Vulnerabilities}

Client participation in both groups brings about uneasiness amongst professionals. The uneasiness is due to a sense of vulnerability or even fear. Abuse of the openness of professionals during MCD is feared. In case I, professionals tend to talk about this, potentially nourishing their reluctance. This results in a pragmatic decision of the manager to introduce client participation despite the feelings expressed. Caught in this decision, the issues of vulnerability, fear, and doubts remain latent throughout the sessions amongst professionals. Professionals tend to hold back in openness and frankness. Rather than raising this issue during the sessions, contraindications for client participation are formulated outside the MCD meetings, behind the scenes. This brings about vulnerability in the position of the client participant: he does not feel part of the group, and feels he should stick to his position despite of the judgements he senses professionals make concerning his presence (due to limitations of the study the impact on client participants and their experience of vulnerability did not become fully clear. Future study on this subject would be desirable). In the second case there is little discussion about the 
background of other group members. Although the same issues concerning vulnerability come up, the issue on former or possible future admissions is not mentioned. Rather, participants feel uneasy sharing their thoughts on a case with people they do not know yet, be it clients or colleagues. Feelings of vulnerability are related to the subject of the sessions, and are relevant for all participants. No criteria for participation are mentioned, not even when, in the so called 'open groups', clinically admitted clients join sessions. Reflection on positions and personal considerations is in concert with the principles of MCD. In this process, frankness increases and casuistry can be explored in an atmosphere of openness and transparency.

\section{Discussion: Dialogue on Quality and Conditions of Dialogue}

Both cases show that client participation in MCD is precarious, since it involves reluctance, vulnerability and even fear. Yet, this empirical finding is not in itself a contra-indication for the normative ideal of client participation in MCD. Feelings of fear and vulnerability may decrease over time. This indicates that a pragmatist approach is desirable: if we do not just do it, it will never be realized. Only talking about client participation seems to stifle learning, while actually undergoing the experience of client participation invites participants to confront both positive and negative feelings and disjunctions which trigger learning and dialogue. Ideally, judgements about client participation should be made after the actual experience of client participation in MCD. However, just starting the process in the expectation that reluctance will automatically diminish is not enough either. Throughout the whole of the process, space should be created to reflect on experiences, especially at those moments when sentiments (re)occur.

Equality in numerical representation ('proportional deliberation', Karpowitz et al. 2009) and a focus on a specific theme contributes positively to the quality of the dialogue. Secondly, a climate is required in which the group (professionals and client participants) can openly reflect on hesitations and fears regarding client participation. These hesitations should openly be addressed during the MCD sessions themselves, taking into account there might be feelings of reluctance in speaking frankly - an issue mentioned in various publications on client participation (Stidham et al. 1990; Neitzke 2009; Rari and Fournier 2009). As in every MCD, any normative ideal should not be taken for granted but reflected upon regarding its concrete meaning for participants (as is the case with client participation).

By conducting our empirical research we learned that dialogue is an active verb. Just starting MCD (in which dialogue is a means and an end) does not automatically guarantee a dialogue. Like all transdisciplinary collaborations client participation seldom appears to be a smooth process (Abma et al. 2009b; Holmesland et al. 2010). Although it does bring in new and valuable perspectives (Cohen and d'Oronzio 1989), we also need to be very alert that our own 'academic,' white, verbal and rationalist notions of dialogue and deliberation are not creating barriers for others to engage and involve with us (Abma 2006; Barnes 2008). Serious inclusion of newcomers in clinical ethics might also mean considering more embodied and 
creative forms of deliberation. Welcoming newcomers therefore needs careful consideration and process management. Client participation itself both requires and stimulates reflection as well as dialogue. The prima facie starting points of MCD (open dialogue and equal participation with respect to moral understanding) make MCD an attractive platform for establishing equality of voices, exploring and acknowledging reluctance and/or vulnerability, thinking through preconditions for co-operation and participation and opening up for new perspectives in order to sharpen individual presuppositions. The explicit and experiential learning processes in MCD makes MCD a good vehicle for implementing client participation within healthcare organizations in a broader sense.

\section{Conclusion}

Client participation is a laudable concept or ideal, yet it requires pragmatist and dialogical work from the very start, constantly reflecting upon the meaning of (conditions for) a good dialogue. As such MCD provides a good context for the introduction of client participation, as dialogue is its core feature. Likewise, client participation puts the essentials of MCD to the test by challenging the basic values of MCD such as safety, frankness, sharing power and control and inclusion. Regarding these founding values for a good dialogue, client participation creates extra challenges to the organization, preconditions and quality of the dialogue. The MCD values of equality of voices, being open and receptive towards fellow participants and postponing judgements can be demanding aspects of MCD. Fostering and maintaining a qualitative dialogue therefore requires ongoing care and attention throughout the introduction of client participation and the process of the actual deliberating. If these dialogical values are not met, client participation in MCD risks turning into pseudo participation or participation out of politeness. Therefore, it requires a truly open conversation, providing space for feelings of vulnerability, inequality or even reluctance during the process of client participation on the spot. This cannot be done without a pragmatic attitude towards realizing participation of all voices and creating preconditions for good participation and dialogue. The pragmatic attitude consists of discussing actual challenges of client participation, not abstract (obstacles of) ideals. It also consists of starting with dialogue on dialogue from the very beginning, thereby preventing the paradox of talking about conditions for dialogue without having a dialogue. If this attitude is present, the ongoing dialogical process of joint learning concerning client participation is not a distant ideal anymore but starts right away.

Acknowledgments This research could be realized due to the inspiring ongoing cooperation between GGNet and the Moral Deliberation Group of the Free University Medical Centre, Amsterdam. We wish to thank all GGNet (client) participants, local coordinators, managers and MCD facilitators who participated in this research.

Open Access This article is distributed under the terms of the Creative Commons Attribution Noncommercial License which permits any noncommercial use, distribution, and reproduction in any medium, provided the original author(s) and source are credited. 


\section{References}

Abma, T. A. (2006). Patients as partners in health research. Evaluation and the Health Professions, 29(4), 424-439.

Abma, T., Molewijk, B., \& Widdershoven, G. A. M. (2009a). Good care in ongoing dialogue-Improving the quality of care through moral deliberation and responsive evaluation. Health Care Analysis, 17(3), 217-235.

Abma, T. A., Nierse, C., \& Widdershoven, G. A. M. (2009b). Patients as research partners in responsive research. Methodological notions for collaborations in research agenda setting. Qualitative Health Research, 19(3), 401-415.

Agich, G. J. (1991). For experts only? Access to hospital ethics committees. The Hastings Center Report, $21,17-25$.

Aulisio, M. P., Arnold, R. M., \& Youngner, S. J. (Eds.). (2003). Ethics consultation from theory to practice. Baltimore, MD: The John Hopkins University Press.

Barnes, M. (2008). Deliberating with care: Ethics and knowledge in the making of social policies. Inaugural lecture, University of Brighton, 24th April 2008.

Bohm, D. (1996). On dialogue. New York: Routledge.

Charmaz, K. (2000). Grounded theory. Objectivist and constructivist methods. In N. K. Denzin \& Y. S. Lincoln (Eds.), Handbook of qualitative research (2nd ed., pp. 509-535). Thousand Oaks, London: Sage.

Cohen, C. J., \& d'Oronzio, J. C. (1989). The question of access. HEC Forum, 1(2), 89-103.

Dauwerse, L., Abma, T., Molewijk, B., \& Widdershoven, G. (2011). Needs for ethics support in healthcare institutions. Views of Dutch board members and ethics support staff. Journal For Medical Ethics. doi:10.1136/jme.2010.040626.

Førde, R., \& Hansen, T. W. R. (2009). Involving patients and relatives in Norwegian clinical ethics committee; what have we learned? Clinical Ethics, 4(3), 125-130.

Fournier, V., Rari, E., Førde, R., Neitzke, G., Pegoraro, R., \& Newson, A. J. (2009). Clinical ethics consultation in Europe: A comparative and ethical review of the role of patients. Clinical Ethics, $4(3), 131-138$.

Gadamer, H. (1960). Wahrheit und methode (Truth and method). Tubingen: J.C.B. Mohr.

Greene, J. (1988). Stakeholder participation and utilization program evaluation. Evaluation Review, 12(2), 91-116.

Greene, J. (2001). Dialogue in evaluation; a relational perspective. Evaluation, 7(2), 181-203.

Guba, E. G., \& Lincoln, Y. S. (1989). Fourth generation evaluation. London: Sage.

Holmesland, A. L., Seikkula, J., Nilsen, O., Hopfenbeck, M., \& Arnkil, E. T. (2010). Open dialogues in social networks: Professional identity and transdisciplinary collaboration. International Journal of Integrated Care, 10, e53.

Irvine, R., Kerridge, I., \& McPhee, J. (2004). Towards a dialogical ethics of interprofessionalism. Postgraduate Medical Journal, 50(4), 278-280.

Karpowitz, C. F., Raphael, C., \& Hammond, A. S. (2009). Deliberative democracy and inequality; two cheers for enclave deliberation among the disempowered. Politics \& Society, 37(4), 576-615.

Kolb, D. A., Baker, A. C., \& Jensen, P. J. (2002). Conversation as experiential learning. In A. C. Baker, P. J. Jensen, \& D. A. Kolb (Eds.), Conversational learning. An experiential approach to knowledge creation (pp. 1-28). Westport, CT: Quorum Books.

Maxwell, J. A. (1996). Qualitative research design: An interactive approach. Thousand Oaks, CA: Sage.

Molewijk, B., Abma, T., Stolper, M., \& Widdershoven, G. (2008a). Teaching ethics in the clinic. The theory and practice of moral case deliberation. Journal for Medical Ethics, 34(2), 120-124.

Molewijk, B., van Zadelhoff, E., Lendemeijer, B., \& Widdershoven, G. (2008b). Implementing moral case deliberation in Dutch healthcare-Improving moral competency of professionals and the quality of care. Bioethica Forum, 1(1), 57-65.

Neitzke, G. (2009). Patient involvement in clinical ethics services: From access to participation and membership. Clinical Ethics, 4(3), 146-151.

Newson, A. J. (2009). The role of patients in clinical ethics support: A snapshot of practices and attitudes in the United Kingdom. Clinical Ethics, 4, 139-145.

Newson, A. J., Neitzke, G., \& Reiter-Theil, S. (2009). The role of patients in European clinical ethics. Clinical Ethics, 4(3), 109-110. 
Paulus, T., Woodside, M., \& Ziegler, M. (2008). Extending the conversation. Qualitative research as dialogic collaborative process. The Qualitative Report, 13(2), 226-243.

Rari, E., \& Fournier, V. (2009). Strengths and limitations of considering patients as ethics "actors" equal to doctors: Reflections on the patient' position in a French clinical ethics consultation setting. Clinical Ethics, 4(3), 152-155.

Reiter-Theil, S. (2003). Balancing the perspectives. The patient's role in clinical ethics consultation. Medicine, Health Care Philosophy, 6, 247-254.

Schicktanz, S., Schwede, M., \& Franzen, M. (2008). 'In a completely different light?' The role of being affected for the epistemic perspectives and moral attitudes of patients, relatives and lay people. Medicine, Health Care Philosophy, 11, 57-72.

Schwandt, T. (2001). A postscript on thinking about dialogue. Evaluation, 2(7), 264-276.

Stake, R. E. (1975). To evaluate an arts program. In R. E. Stake (Ed.), Evaluating the arts in educationA responsive approach (pp. 13-31). Colombus, OH: Merrill.

Stake, R. E. (2004). Standards-based and responsive evaluation. Thousand Oaks, CA: Sage.

Stidham, G. L., Christensen, K. T., \& Burke, G. F. (1990). The role of patients/family members in the hospital ethics committee's review and deliberations. HEC Forum, 2(3), 3-17.

van der Dam, S., Abma, T. A., Molewijk, A. C., Kardol, M. J. M., Schols, J. M. G. A., \& Widdershoven, G. A. M. (2011). Organizing moral case deliberation: Experiences in two Dutch nursing homes. Nursing Ethics, 18(3), 327-340.

Weidema, F., Molewijk, B., Widdershoven, G., \& Abma, T. (2011). Enacting ethics: Bottom-up involvement in implementing moral case deliberation. Health Care Analysis. doi:10.1007/s10728-010-0165-5.

Widdershoven, G., Abma, T., \& Molewijk, B. (2009). Empirical ethics as dialogical practice. Bioethics, 23(4), 236-248. 